\title{
The Talmud in Its Iranian Context
}

\author{
Ed. by Carol Bakhos and Rahim Shayegan
}

[Der Talmud in seinem iranischen Kontext.]

Veröffentlicht auf Englisch.

Gelehrte auf dem Gebiet der Rabbinistik und Iranistik wenden sich zunehmend dem iranischen Kulturraum zu, um die Stärke

The Talmud in Its Iranian Context$$
\text { Edited by }
$$

Edited by CAROL BAKHOS and

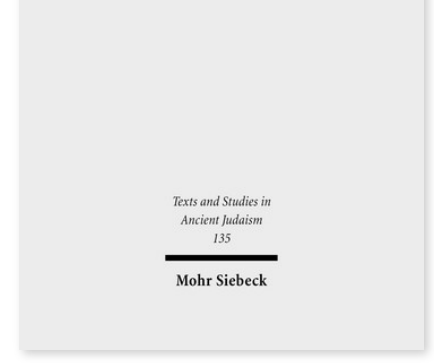

2010. XVIII, 270 Seiten. TSAJ 135

ISBN 978-3-16-151468-5

DOI 10.1628/978-3-16-151468-5

eBook PDF 104,00€

ISBN 978-3-16-150187-6

Leinen $104,00 €$ und Tragweite des Einflusses, den die zoroastrischen Theologie und Liturgie sowie sasanidische Rechtspraktiken auf den babylonischen Talmud ausübten, zu erforschen. Wahrscheinlich kommen zum ersten mal Wissenschaftler von beiden Fachgebieten zusammen, um die wechselseitige Beeinflussung der jüdischen und iranischen Kulturen im Bereiche rechtlicher Exegese, Literatur und religiösen Denkens zu untersuchen. Die Folgerungen/Ergebnisse dieser bahnbrechenden Bemühung sind für die Judaistik und Iranistik von großer Bedeutung.

Carol Bakhos is Associate Professor of Late Antique Judasim at UCLA.

Rahim Shayegan is Assistant Professor of Iranian Studies at UCLA.

Jetzt bestellen:

https://mohrsiebeck.com/buch/the-talmud-in-its-iranian-context-9783161514685?no_cache=1 order@mohrsiebeck.com

Telefon: $+49(0) 7071-923-17$

Telefax: $+49(0) 7071-51104$ 